AperTO - Archivio Istituzionale Open Access dell'Università di Torino

\title{
Dealloying of an Au-based amorphous alloy
}

\section{This is the author's manuscript}

Original Citation:

Availability:

This version is available http://hdl.handle.net/2318/74019

since 2019-11-19T15:52:06Z

Published version:

DOI:10.1016/j.intermet.2010.08.005

Terms of use:

Open Access

Anyone can freely access the full text of works made available as "Open Access". Works made available under a Creative Commons license can be used according to the terms and conditions of said license. Use of all other works requires consent of the right holder (author or publisher) if not exempted from copyright protection by the applicable law. 
Elsevier Editorial System(tm) for Intermetallics

Manuscript Draft

Manuscript Number: INTERMETALLICS-D-10-00070R1

Title: Dealloying of an Au based amorphous alloy

Article Type: Research Paper

Keywords: B. glasses metallic; D. phase interfaces;

F. corrosion behaviour.

Corresponding Author: Dr. Federico Scaglione, Ph.D. Student

Corresponding Author's Institution: Università degli Studi di Torino

First Author: Federico Scaglione

Order of Authors: Federico Scaglione; Annett Gebert; Livio Battezzati

Abstract: The dealloying behaviour of Au42Cu29Ti8Si21 and Au44Cu31Ti4Si21 amorphous (wheel side) and partially crystalline (air side) ribbons was investigated using potentiostatic and galvanostatic etching. The resulting microstructures are: i) on the wheel side homogeneous porosity with size from tens of nanometers to less than $10 \mathrm{~m}$ in between Au crystals is largely found, ii) on the air side the porosity occurs on two length-scales, submicrometer as on the opposite size and micrometer where crystals are removed. The importance of surface morphology in the formation of the microstructure is outlined. The role of diffusion and nucleation in the mechanism of surface gold enrichment is established. 
UNIVERSITA' DEGLI

STUDI DI TORINO

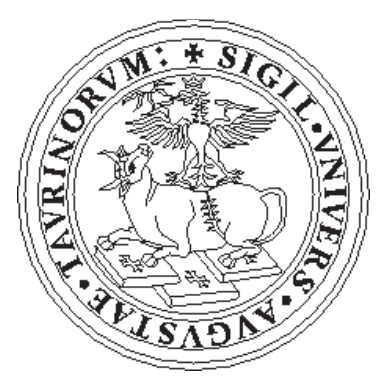

Dipartimento di Chimica Inorganica, Chimica Fisica e

Chimica dei Materiali

Centro di Eccellenza

Superfici ed Interfasi Nanostrutturate

Torino, 23/06/2010

Dear Editor,

I am re-submitting a paper for publication in Intermetallics by my $\mathrm{PhD}$ student F. Scaglione, Dr. A. Gebert of IFW, Dresden, and myself after modifying it according to referees' comments.

The topic covered is novel: formation of porosity by dealloying an amorphous alloy based on Au. We have analysed the role of surface features of ribbons on the mechanism of selective dissolution. With respect to the previous version, we have re-written large part of the text, made further electrochemical checks, changed most figures introducing images of better quality and patterns of better resolution. The analysis of patterns has been extended.

I hope you will find our work of interest.

Sincerely yours

Prof. Livio Battezzati 
Answers to the referees.

The referees made several constructive comments and criticism to the previous version of our paper.

We took advantage of their suggestions and decided to revise the whole work in depth.

Therefore, we do not report single answers to every comment, but state that

- we have re-written large part of the text,

- made further electrochemical checks and microscopy observations to confirm our findings,

- changed most figures introducing images of better quality,

- introduce an image of a cross-section of our material,

- introduced new XRD patterns of better resolution,

- analysed patterns according to the Rietveld method.

Sincerely

The Authors 
1

\title{
Dealloying of an Au based amorphous alloy
}

\author{
Federico Scaglione ${ }^{1}$, Annett Gebert, ${ }^{2}$ Livio Battezzati ${ }^{1}$ \\ ${ }^{1}$ Dipartimento di Chimica IFM e Centro di Eccellenza NIS, Università di Torino, Via P. Giuria 7, 10125 \\ Torino, Italy. \\ ${ }^{2}$ Leibniz-Institute for Solid State and Materials Research (IFW-Dresden), P.O. Box 270016, D-01171 \\ Dresden, Germany.

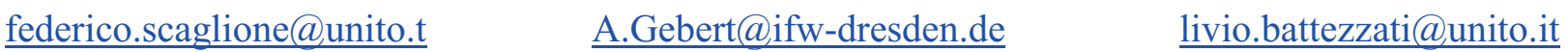

\begin{abstract}
The dealloying behaviour of $\mathrm{Au}_{42} \mathrm{Cu}_{29} \mathrm{Ti}_{8} \mathrm{Si}_{21}$ and $\mathrm{Au}_{44} \mathrm{Cu}_{31} \mathrm{Ti}_{4} \mathrm{Si}_{21}$ amorphous (wheel side) and partially crystalline (air side) ribbons was investigated using potentiostatic and galvanostatic etching. The resulting microstructures are: i) on the wheel side homogeneous porosity with size from tens of nanometers to less than $1 \mu \mathrm{m}$ in between Au crystals is largely found, ii) on the air side the porosity occurs on two length-scales, submicrometer as on the opposite size and micrometer where crystals are removed. The importance of surface morphology in the formation of the microstructure is outlined. The role of diffusion and nucleation in the mechanism of surface gold enrichment is established.
\end{abstract}

KEYWORDS: B. glasses metallic; D. phase interfaces; F. corrosion behaviour .

\section{Introduction}


Dealloying is a phenomenon of corrosion where the less noble metal is selectively removed from an alloy. This technique has recently gained interest for tailoring nanoporous metallic materials aiming at improved properties in various field such as catalysis, sensors, hydrogen storage, molecular sieves. The main features required for nanoporous metals are interconnected pores and tunnels together with fine crystallites, i. e. a spongy-like material made of an almost pure inert metal $[1,2]$.

The dealloying of crystalline alloys has been studied in a number of works, most of them involving binary systems, especially $\mathrm{Au}-\mathrm{Cu}[3]$ and $\mathrm{Au}-\mathrm{Ag}[4,5]$. Aspects of the mechanisms and parameters controlling the dealloying process have been identified: the need of a substantial difference in electrochemical potential between alloy components, the role of a critical potential in the morphology of corrosion, the existence of a "parting limit", i.e. a limiting content of the most noble element which is usually less than that of the less noble one, the alternative mechanisms of surface and volume diffusion of the more noble species $[1,2,6-10]$. Since dealloying has been studied in homogeneous crystalline solid solutions, it is of interest to investigate how it occurs in amorphous alloys. These are more complex in composition than the crystalline alloys usually employed for selective dissolution, both because of the number of elements and of the amorphous structure made of ordered clusters interconnected at short range. On a larger length scale, while grain boundaries and other lattice defects emerge on the polished surface of a crystalline alloy, and roughness and grooves can provide centres for preferential etching, amorphous alloys do not contain grain boundaries. Considering rapid solidification in the form of ribbons, however, their surface may still present zones prone to preferential etching due to morphologies related to the quenching process, e. g. difference of the two sides of ribbons being either smooth and shiny or corrugated and dull, quenched-in crystals and even nuclei. Studies have recently been conducted on the dealloying behaviour of $\mathrm{Pd}_{30} \mathrm{Ni}_{50} \mathrm{P}_{20}$ glassy ribbons by electrochemical etching [11], on free corrosion of Cu-Zr-Ti bulk metal glasses in hydrofluoric acid [12] and on Ti-Y-Al-Co phase-separated glass after immersion in sulphuric acid [13] showing in all cases the depletion of the less noble elements and the formation of nanoporous structures. Dealloying was also briefly shown to be feasible in a multicomponent Au-alloy, $\mathrm{Au}_{35} \mathrm{Si}_{20} \mathrm{Cu}_{28} \mathrm{Ag}_{7} \mathrm{Pd}_{5} \mathrm{Co}_{5}[11]$. 
Au-based metallic glasses derive from the Au-Si binary and $\mathrm{Au}-\mathrm{Cu}-\mathrm{Si}$ ternary eutectics. It has been recently shown that the addition of $\mathrm{Ti}$, having a strongly negative heat of mixing with $\mathrm{Au}$ and $\mathrm{Si}$, improves the glass forming ability of the ternary system, although the resulting alloy is not a bulk glass former $[14,15]$. Ribbons were obtained with the $\mathrm{Au}_{42} \mathrm{Cu}_{29} \mathrm{Ti}_{8} \mathrm{Si}_{21}$ and $\mathrm{Au}_{44} \mathrm{Cu}_{31} \mathrm{Ti}_{4} \mathrm{Si}_{21}$ compositions closer to the parting limit for dealloying than previous cases. They display a gradient of microstructure from the amorphous wheel side to the air side where quenched-in crystals are found. The aim of this work is the study of dealloying of such alloys, to learn on the effect of structural differences between ribbon surfaces, including surface roughness.

\section{Experimental}

$\mathrm{Au}_{42} \mathrm{Cu}_{29} \mathrm{Ti}_{8} \mathrm{Si}_{21}, \mathrm{Au}_{44} \mathrm{Cu}_{31} \mathrm{Ti}_{4} \mathrm{Si}_{21}$ ingots were prepared by arc-melting the pure elements (Au: $99.99 \%$, Cu: 99.99\%, Si: 99,9995\%, Ti:99.99\%) in argon atmosphere and using Ti getters. Ribbons about $25 \mu \mathrm{m}$ thick and $2 \mathrm{~mm}$ wide were obtained by melt spinning with a linear velocity of the copper wheel of 22 $\mathrm{m} / \mathrm{s}$. Samples of $15 \mathrm{~mm}$ in length were cut from ribbons. Preliminary surface investigation shows the expected difference in morphology on two sides: the side in contact with the argon atmosphere (called air-side) has a shiny and bright surface, in addition wavy patterns are recognized possibly marking the liquid flow prior to freezing; the side in contact with the copper wheel of the spinner is dull and shows longitudinal roughness due to the surface finish of the wheel and elongated cavities due to trapping of gas between the wheel and the alloy (Fig. $1 \mathrm{a}$ and $\mathrm{b}$ ).

For electrochemical dealloying, samples have been used as working electrode in a cell composed of a Standard Calomel reference electrode (SCE) and a Pt counter electrode in a Potentiostat/Galvanostat Model 7050, Amel Instruments. The critical potential for dealloying $\mathrm{E}_{\mathrm{c}}$ has been determined by performing anodic polarization experiments [16]; because of the similar amount of Au, the critical potential of the samples is close to each other $\left(1,75 \mathrm{~V}\right.$ for $\mathrm{Au}_{42} \mathrm{Cu}_{29} \mathrm{Ti}_{8} \mathrm{Si}_{21}$ and $1,77 \mathrm{~V}$ for $\left.\mathrm{Au}_{44} \mathrm{Cu}_{31} \mathrm{Ti}_{4} \mathrm{Si}_{21}\right)$. 
The dealloying behaviour of alloys has been investigated using potentiostatic and galvanostatic methods in an electrolyte made of a $0.1 \mathrm{M} \mathrm{HNO}_{3}$ aqueous solution; in the former, samples have been etched for 20 hours at 1,90 V (vs the SCE electrode), in the latter, samples have been etched at $15 \mathrm{~mA}$ for 6 hours. Samples have been analyzed before and after etching using X-ray diffraction (XRD) in Bragg-Brentano geometry with monochromatic $\mathrm{Cu} \mathrm{K} \alpha$ radiation, scanning electron microscopy (SEM), Energy Dispersive X-ray Spectroscopy (EDS) (calibrated with a pure Co sample) and Auger electron spectrometry (AES) with sputtering rate $2.8 \mathrm{~nm} / \mathrm{min}$ for times up to $15 \mathrm{~min}$.

\section{Results}

XRD patterns of the as-spun ribbons are shown in Fig. 2. The wheel side appears fully amorphous whereas on the air-side some crystal reflections are superimposed to the amorphous halo. Their number is limited and the intensity is high only for two of them suggesting they belong to textured crystals of a high symmetry phase. Actually, the interplanar spacing of the one occurring at higher angle is double of that of the other one. EDS analyses indicate the crystals are rich in $\mathrm{Cu}$ and $\mathrm{Si}$ and are mostly located in small patches along the wavy patterns shown in Fig. 1b. The spacings of such reflections are compatible with those of a cubic phase, $\mathrm{Cu}_{15} \mathrm{Si}_{4}$ type [17] which is identified by comparison with other ribbons of $\mathrm{Au}_{37.5} \mathrm{Cu}_{37.5} \mathrm{Si}_{25}$ composition and is metastable in all these rapidly quenched alloys. It should also be mentioned that on both sides a few tiny crystals rich in $\mathrm{Ti}$ and $\mathrm{Si}$ have been found far from each other and randomly localized. No XRD reflection could be seen and assigned to them, possibly because of their low amount. From analogy with previous studies [15] they are identified as $\mathrm{Ti}_{5} \mathrm{Si}_{3}$. Confirmation of the difference in microstructure between the two sides comes from crystallisation studies of the alloys. Microscopy and XRD showed that the crystals on the air side at first grow and then transform to equilibrium phases on annealing above $150{ }^{\circ} \mathrm{C}$, whereas no apparent sign of surface or sub-surface crystallisation was detected on the wheel side. This should have initiated the transformation in case of the presence of a fraction of crystalline phases after quenching, even if not detected by XRD. Of course, 
the occurrence of quenched-in nuclei can never be ruled out in amorphous alloys.

The $\mathrm{Cu}_{15} \mathrm{Si}_{4}$ crystals are quickly removed by electrochemical etching so that their reflections fully disappear from the diffraction pattern (Fig. 2) while leaving an incipient porosity of micrometer size on the ribbon surface. With prolonged treatment, the ribbon becomes brown coloured and more brittle than before etching. XRD patterns show that gold rich crystals were obtained on both sides of the ribbon surfaces. The amorphous halo of the underlying glassy phase is still well recognized in the patterns (Fig.2 b and d). Some patterns were analysed according to the Rietveld method [18] after numerically subtracting the contribution of the amorphous halo. The lattice constant of gold crystals is undistinguishable with respect to that of pure gold within the data scatter. Values of the size of the scattering domains of the gold phase varied from $53 \mathrm{~nm}$ to $107 \mathrm{~nm}$ according to the pattern being analysed. The root mean square of the microstrain was comprised between $0.6 \cdot 10^{-3}$ and $2.6 \cdot 10^{-3}$.

SEM images taken on the air-side of the $\mathrm{Au}_{42} \mathrm{Cu}_{29} \mathrm{Ti}_{8} \mathrm{Si}_{21}$ ribbon after potentiostatic etching, show details appreciable on different scales: the meso-scale porosity, due to the removal of the crystalline phase and finer porosity in between pure Au particles connected to each other (Fig. 3a). Features related to the pre-existing roughness are also recognized, especially on the wheel-side which is mostly covered by a homogeneous carpet of porous gold with longitudinal hillocks and isolated channels (Fig. 3b). Increasing the magnification it is evidenced that the interconnected particles are similar in shape to those present on the air side. Their size is of the order of a few hundreds of nanometers (Fig. 3c, 3d), therefore. they must contain finer scattering domains of the size assessed from the XRD patterns.

A cross section view of a dealloyed ribbon cut with a scalpel is reported in Fig. 3e. On the wheel-side where the cut started, the dealloyed layer was detached from the matrix which displays a featureless zone due to shear offset and a rather brittle fracture surface ending at the dealloyed layer on the air side. The layers are about $5 \mu \mathrm{m}$ thick.

Microanalysis has been performed on both sides of the dealloyed ribbons showing considerable surface enrichment in gold and depletion in copper while the titanium and silicon percentage was on average decreased less. This result is not in contrast with the XRD pattern that shows reflections of pure 
gold after dealloying: because of the penetration of the electron beam, microanalysis data should be intended as giving an average composition between the dealloyed surface layer, composed of pure gold, and the layers below that have not been etched yet. Elemental maps showed enrichment of $\mathrm{Si}$ in the pores accompanied by a higher Oxygen signal. Ti was more concentrated as well, although less homogeneously distributed. Fine spot EDS analyses confirmed that $\mathrm{Si}$ and Ti are localized, together with Oxygen in the pores seen in the SEM images.

The surfaces were chemically analysed with AES that, compared to EDS, penetrates less deeply into the sample, giving information on the top layers. Again, the information comes from both the protruding network of crystals and pores. AES data, collected from areas of the order of a few hundred square microns, confirm the EDS results. In fact, strong gold enrichment and depletion of the other elements was measured. Enrichment in $\mathrm{Si}$ and $\mathrm{O}$ was found for about $25 \mathrm{~nm}$, before obtaining a steady compositional profile consisting of $76 \%$ at $\mathrm{Au}, 13 \%$ at $\mathrm{Si}, 7 \%$ at $\mathrm{O}, 3 \% \mathrm{Cu}, 1 \%$ at Ti. Note that, $\mathrm{AES}$ analysis of the as-quenched ribbon gave values close to the alloy nominal composition for all elements at the steady state. Here the top $20 \mathrm{~nm}$ are definitely rich in $\mathrm{Si}$ and $\mathrm{O}$. The Oxygen contamination remains below $4 \%$ at in the bulk.

The current density varied slightly in different experiments being of the order of tens of $\mathrm{mA} / \mathrm{cm}^{2}$. It then decreased slowly becoming almost halved after about 50 minutes and then remaining substantially constant during the etching time ( 20 hours). This passivating effect is likely due both to surface gold enrichment and progressive coverage and to enrichment in $\mathrm{Si}$ and $\mathrm{Ti}$ in the pores, possibly as oxides. Dealloying was therefore slow and did not extended to the whole thickness of the ribbon during the time of the experiments.

Similar results have been obtained on the $\mathrm{Au}_{44} \mathrm{Cu}_{31} \mathrm{Ti}_{4} \mathrm{Si}_{21}$ ribbon.

Galvanostatic etching for 6 hours also produced diffuse porosities on the air-side of the $\mathrm{Au}_{42} \mathrm{Cu}_{29} \mathrm{Ti}_{8} \mathrm{Si}_{21}$ ribbon within fine Au particles interconnected with ligaments (Fig. 4 a, 4c). The lattice parameter of these crystals is that of pure gold. On the wheel-side Au concretions are found throughout the sample. They appear to have grown to a large extent in the third dimension and are separated by cracks and 
channels (Fig. 4 b); higher magnification images show that concretions are actually assemblies of gold particles (Fig. 4 c). Their crystal size is in the range reported above for the potentiostatic method on both sides. Analogously, the microanalytical data show gold enrichment and localisation of $\mathrm{Si}$ and $\mathrm{Ti}$ as oxides in the deeper porosity.

Similar results has been obtained with the $\mathrm{Au}_{44} \mathrm{Cu}_{31} \mathrm{Ti}_{4} \mathrm{Si}_{21}$ ribbon as for the morphology of the layers and for their gold content.

\section{Discussion}

Electrochemical etching of $\mathrm{Au}_{42} \mathrm{Cu}_{29} \mathrm{Ti}_{8} \mathrm{Si}_{21}$ and $\mathrm{Au}_{44} \mathrm{Cu}_{31} \mathrm{Ti}_{4} \mathrm{Si}_{21}$ amorphous ribbons causes surface enrichment of gold but with different aspect on the opposite sides: porosity on two length scales together with interconnected particles rich in gold develop on the air-side while coarse concretions grow on the wheel-side. This different behaviour can be related to the initial morphology of the surface before etching. The air-side is initially not homogeneous due to the presence of the crystallised $\mathrm{Cu}_{15} \mathrm{Si}_{4}$-type phase. Its removal induces the formation of micron sized porosity, the neighbouring areas of which provide centres for preferential etching with development of the finer microstructure. On the wheel-side, where such inhomogeneity is not present, the etching follows the extensive longitudinal roughness due to the contact with the quenching wheel. The rare Ti-Si crystals found on both sides do not appear to influence the etching and the resulting microstructure.

High magnification images of ribbon sides show that ligaments and concretions are made of similar gold particles in both potentiostatic and galvanostatic experiments with porosity of similar average dimension from tens of nanometers to less than $1 \mu \mathrm{m}$. The Au crystals display a relatively low overall strain confirming previous findings obtained with an $\mathrm{Au}-\mathrm{Ag}$ alloy chemically dealloyed in nitric acid. $[10]$.

Three mechanisms for the formation of porosity after selective dissolution of the less noble metal have been outlined [19]: surface diffusion of the more noble metal until a dense layer prevents further anodic 
dissolution, volume diffusion involving ionization of the less noble metal and diffusion of atoms from the bulk, dissolution of all element with the re-deposition of the noble one. In the present work, considering the morphology of the particles formed on both sides of the ribbon in all etching methods, it is possible to hypothesize that the occurrence of three dimensional aggregates of gold particles imply continuous diffusion of gold. At first, contrary to dealloying of crystalline alloys composed already of a single face-centered cubic phase, nucleation of gold crystals must occur. The distribution of the resulting crystals suggests the nucleation takes place heterogeneously on emerging asperities. The evidence of repeated nucleation, growth of gold nanocrystals and their build up into ligaments and concretions points to a continuous role of surface diffusion soon after the less noble elements are dissolved. Volume diffusion can also be envisaged for letting the gold emerge to the surface, but it is less likely to be effective: in fact, it should cause the formation of crystallization products of the alloy (i. e. gold silicides [15]), at least temporarily, in the bulk which have never been found here, not even occasionally. At last, it is possible to exclude the dissolution/re-deposition mechanism because, under the applied electrochemical condition, gold does not dissolve or dissolve very slowly. The role of the initial amorphous structure appears marginal. Once the less noble components are removed, nucleation of gold crystals must be very quick, being facilitated by local heterogeneity and the apparent fast surface diffusion.

The occurrence of crack patterns following electrochemical etching are frequently reported in the literature $[20,21]$ associated to the phenomenon of stress corrosion cracking (SSC). This is particularly evident in systems like $\mathrm{Au}-\mathrm{Cu}, \mathrm{Cu}-\mathrm{Zn}$ and $\mathrm{Cu}-\mathrm{Mg}$, where micrometric fractures spread along low index crystallographic planes. SCC in ribbons could be induced by the misfit and volume reduction between the dealloyed layers and the substrate alloy that has not been dealloyed yet, causing embrittlement. Chemical analysis and mapping showed that inside the pores the average composition contains an excess of silicon, titanium and oxygen amount than the other zones of the ribbons, probably contributing to passivity of the alloy as supported by the decrease of the current density versus time in the 
potentiostatic method. Since oxide particles were never identified either on top views and cross sections of the ribbons, it is deduced that the oxides cover the remaining amorphous phases in thin layer form.

In a recent work a bimodal size of porosities has been obtained by chemically dissolving the $\mathrm{Al}$ in $\mathrm{Au}-$ Al melt spun crystalline ribbons with either hydrochloric acid or sodium hydroxide [22]. The larger intergranular channels are due to removal of crystals or dendrites of the Al-richer phase whereas the finer ligaments and porosities, ranging from 10 to $80 \mathrm{~nm}$ in size, are originated by dissolution of the $\mathrm{Al}_{2} \mathrm{Au}$ intermetallic compound. The microstructures obtained in the present work show, especially on the air side, more interconnected distributions of large channels and fine ligaments and porosities. These could further be tuned by controlled crystallization of the amorphous alloy.

\section{Conclusions}

Dealloying of Au-based metallic glasses has been studied with potentiostatic and galvanostatic methods. Both etchings lead to surface enrichment of gold with formation of ligaments and micrometric porosity on the air-side and concretions and channels on the wheel-side. High magnification images show that ligaments and concretions are assemblies of finer gold particles.

The morphology of the surface and its homogeneity appear as key parameters in dealloying. The airside of the ribbon is smooth but not chemically homogeneous. Here, the removal of a crystalline phase (possibly $\mathrm{Cu}_{15} \mathrm{Si}_{4}$-type) provides centres for preferential etching with development of fine ligaments and porosity. The wheel side is more chemically homogeneous but rough. Again the etching is favoured on surface asperities. The removal of alloy components from the glassy matrix causes the likely heterogeneous nucleation of the face centred cubic gold. Although the morphology of gold aggregates differs on the two sides, they are composed of scattering domains of the same size, of the order of 25 $\mathrm{nm}$. Surface diffusion has been hypothesized as the mechanism leading to the observed structures.

The present results indicate that porous nanocrystalline gold for functional application can be obtained from amorphous alloys. They also suggest that improving the surface homogeneity or, on the opposite, 
surface modification such as partial crystallisation can be used to obtain dealloyed layers with porosity of varied size.

\section{Acknowledgements}

Work performed for "Progetto D23, Bando Regionale Ricerca Scientifica Applicata 2004". Fondazione S. Paolo is acknowledged for support to CdE NIS. 


\section{REFERENCES.}

[1] M. Stratmann and M. Rohwerder, Nature, 410 (2001) 420-423.

[2] J. Erlebacher and R. Seshadri eds, Hard Materials with tunable Porosity, MRS Bulletin, 34(8) (2009) 561-566.

[3] J. D. Fritz and H. W. Pickering, J. Electrochem. Soc., 138(11) (1991) 3209-3218.

[4] X. Lu, E. Bischoff, R. Spolenak and T. J. Balk, Scripta Materialia, 56 (2007) 557-560.

[5] J. Erlebacher, M. J. Aziz, A. Karma, N. Dimitov, K. Sieradzki, Nature, 410 (2001) 450-453.

[6] H. W. Pickering and P. J. Byrne, J. Electrochem. Soc., 118 (1971) 209-215.

[7] J. Rugolo, J. Erlebacher and K. Sieradzki, Nature Materials, 5(12) (2006) 946-949.

[8] J. Erlebacher and K. Sieradzki, Scripta Materialia, 49 (2003) 991-996.

[9] C. Ji and P. C. Searson, J. Phys. Chem. B, 107 (2003) 4494-4499.

[10] S. Van Petegem, S. Brandstetter, R. Maass, A. M. Hodge, B. S. El-Dasher, J. Biener, B. Schmitt,

C. Borca and H. Van Swygenhoven, NanoLetters, 9 (2009) 1158-1163.

[11] J. Yu, Y. Ding, C. Xu, A. Inoue, T. Sakurai and M. Chen, Chem. Mater., 20 (2008) 4548-4550.

[12] H. Abe, K. Sato, H. Nishikawa, T. Takemoto, M. Fukuhara and A. Inoue, Materials Trans., 50 (2009) 1255-1258.

[13] J. Jayaraj, J. M. Park, P.F. Gostin, E. Fleury, A. Gebert, L. Schultz, Intermetallics, 17 (2009) $1120-1123$.

[14] G. Fiore, L. Battezzati, Rev. Adv. Mater. Sci., 18 (2008) 190-192.

[15] G. Fiore, I. Ichim, L. Battezzati, J. of Physics: Conf. Series, 144 (2009) 012039. 
[16] H. W. Pickering, Corr. Sci., 23(10) (1983) 1107-1120.

[17] X'Pert HighScore, PANalytical B.V., 2003, file 03-065-3166.

[18] L. Lutterotti, S. Matthies and H.-R. Wenk: MAUD (Material Analysis Using Diffraction) is released under free license of the authors Available at http://www.ing.unitn.it/ maud/index.html .

[19] H. W. Pickering and C. Wagner, J. Electrochem. Soc., 114 (1967) 698-706.

[20] G. S. Duffò, S. B. Farina, J. R. Galvele, Corr. Sci., 46 (2004) 1-4.

[21] J. D. Fritz, B. W. Parks and H. W. Pickering, Scripta Metall., 22(7) (1988) 1063-1068.

[22] Z. Zhang, Y. Wang, Z. Qi, J. Lin, X. Bian, J. Phys. Chem. C, 113 (2009) 1308-1314. 


\section{FIGURE CAPTIONS.}

Fig. 1. The surface of the $\mathrm{Au}_{42} \mathrm{Cu}_{29} \mathrm{Ti}_{8} \mathrm{Si}_{21}$ as-spun ribbon: (a) Secondary electron SEM image of roughness on the wheel-side; (b) Backscattered SEM image of the air-side.

Fig. 2. XRD patterns of the $\mathrm{Au}_{42} \mathrm{Cu}_{29} \mathrm{Ti}_{8} \mathrm{Si}_{21}$ ribbon: a) air-side before and b) after etching at $1,90 \mathrm{~V}$ for $20 \mathrm{~h}, \mathrm{c})$ wheel-side before and d) after etching at $1,90 \mathrm{~V}$ for $20 \mathrm{~h}$. $\nabla \mathrm{Cu}_{15} \mathrm{Si}_{4}$-type phase reflections and $\Delta$ Au reflections.

Fig. 3. SEM images of the $\mathrm{Au}_{42} \mathrm{Cu}_{29} \mathrm{Ti}_{8} \mathrm{Si}_{21}$ ribbon after dealloying with the potentiostatic method. (a) meso-scale porosity and finer porosity in between pure Au connected particles on air-side, (b) carpet of porous gold with longitudinal hillocks and isolated channels on wheel-side, (c) higher magnification images of interconnected particles on the air-side and (d) on the wheel-side, (e) cross-section detail of the ribbon.

Fig. 4. SEM images of the $\mathrm{Au}_{42} \mathrm{Cu}_{29} \mathrm{Ti}_{8} \mathrm{Si}_{21}$ ribbon etched $6 \mathrm{~h}$ at $15 \mathrm{~mA}$ with galvanostatic method. (a) porosity and fine Au particles interconnected with ligaments on the air-side, (b) concretions separated by cracks and channels on the wheel-side, (c) and (d) higher magnification images of ligaments and concretions constituted by gold particles on the wheel-side. 

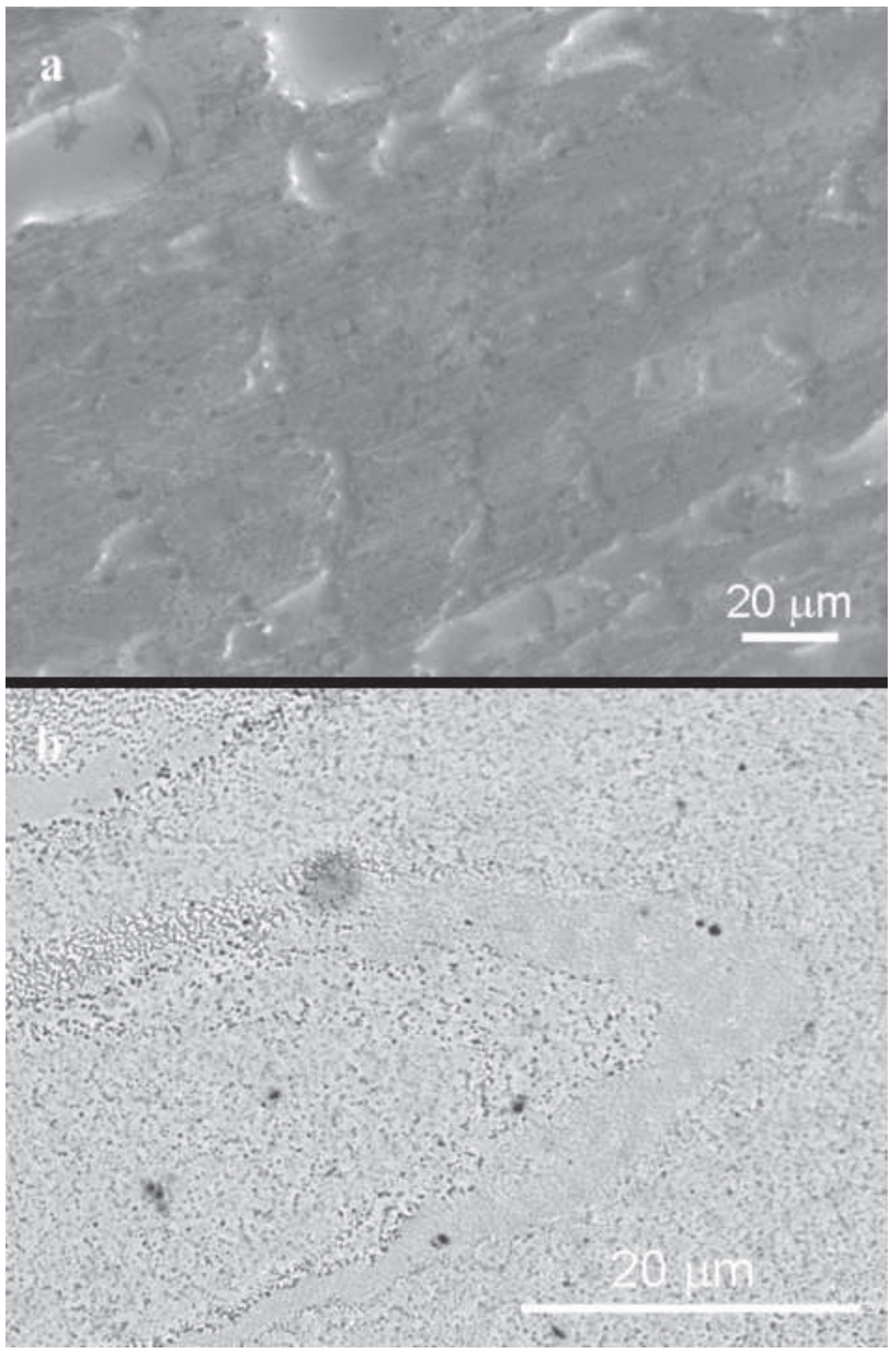


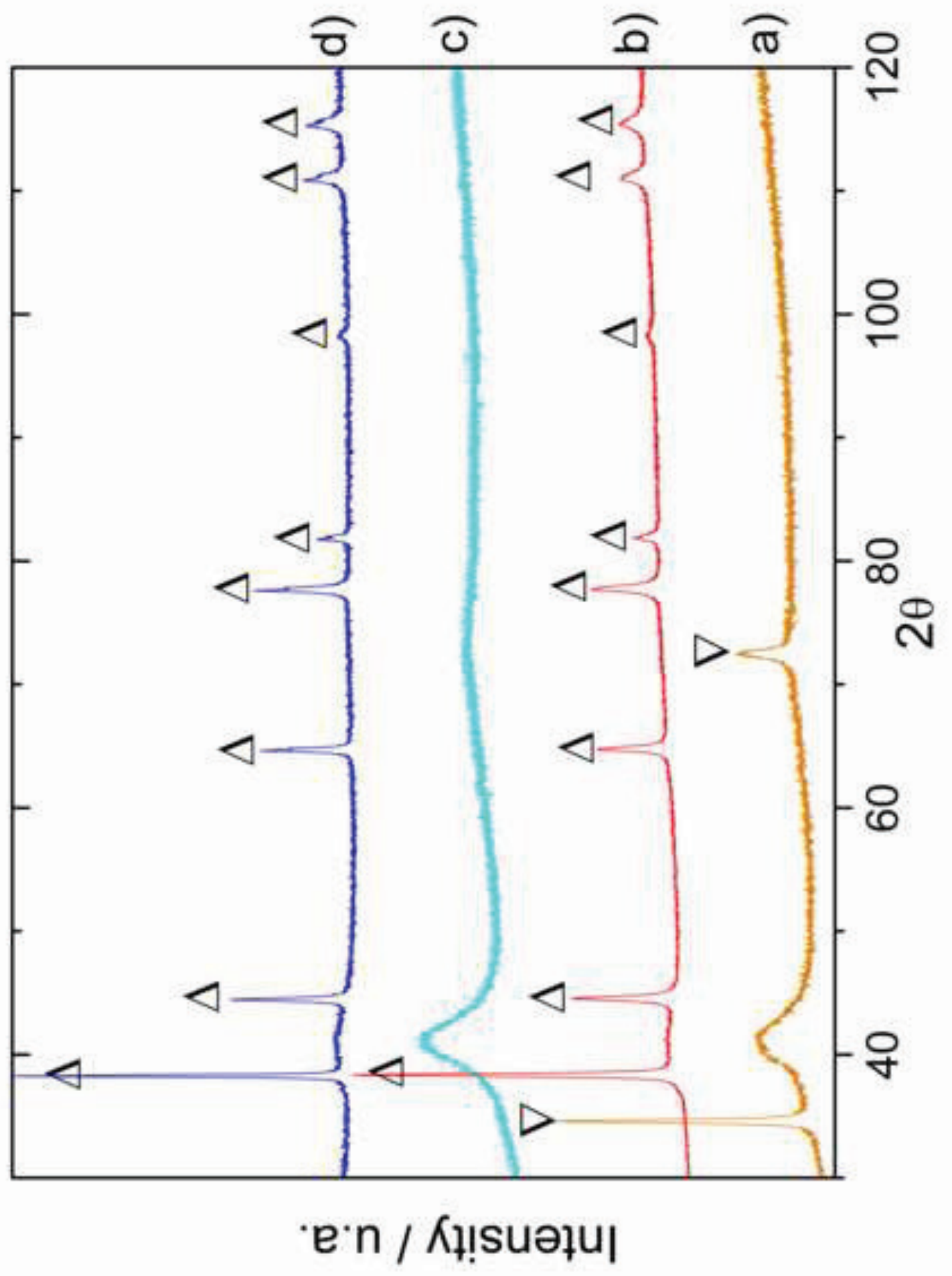




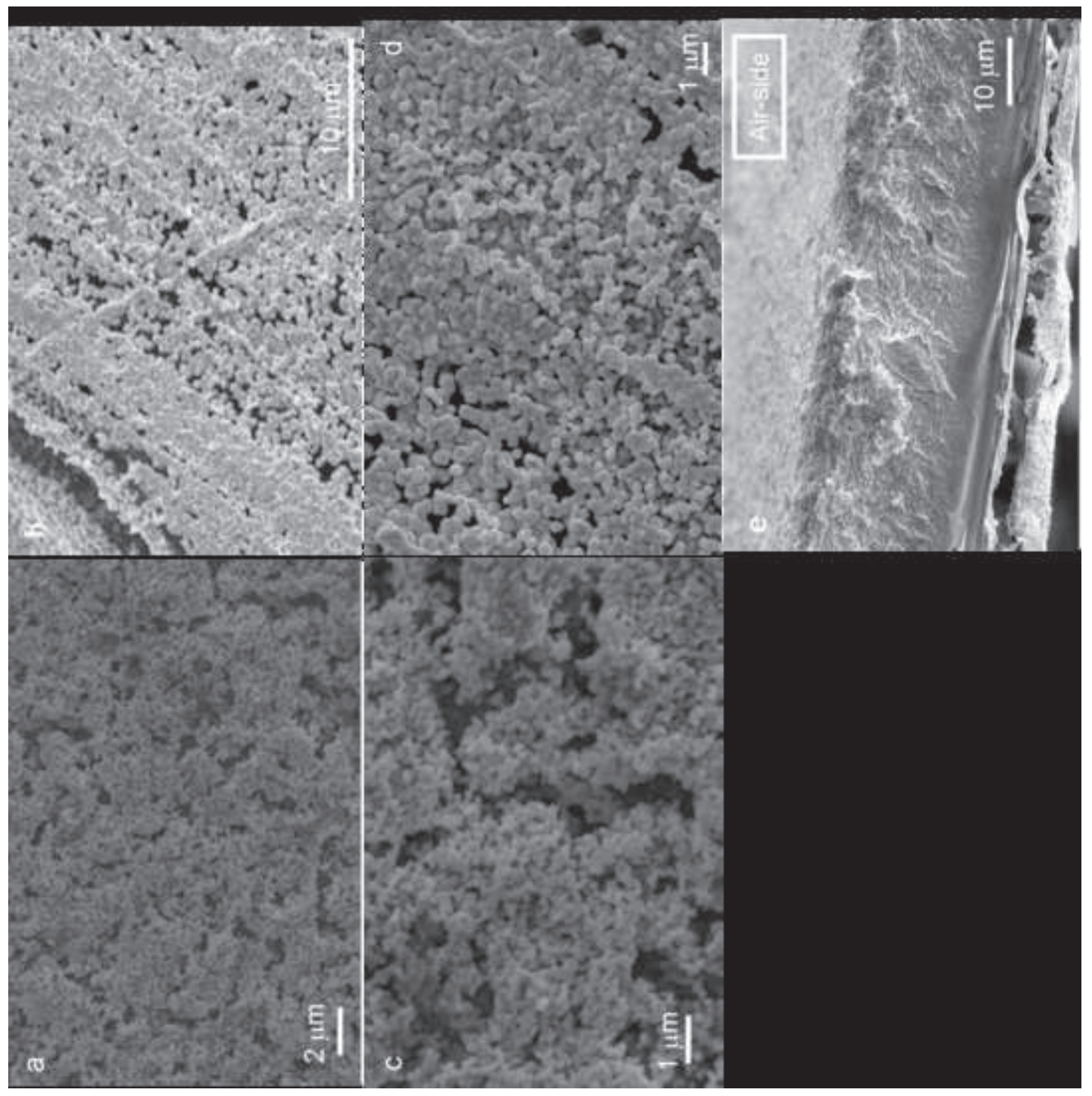



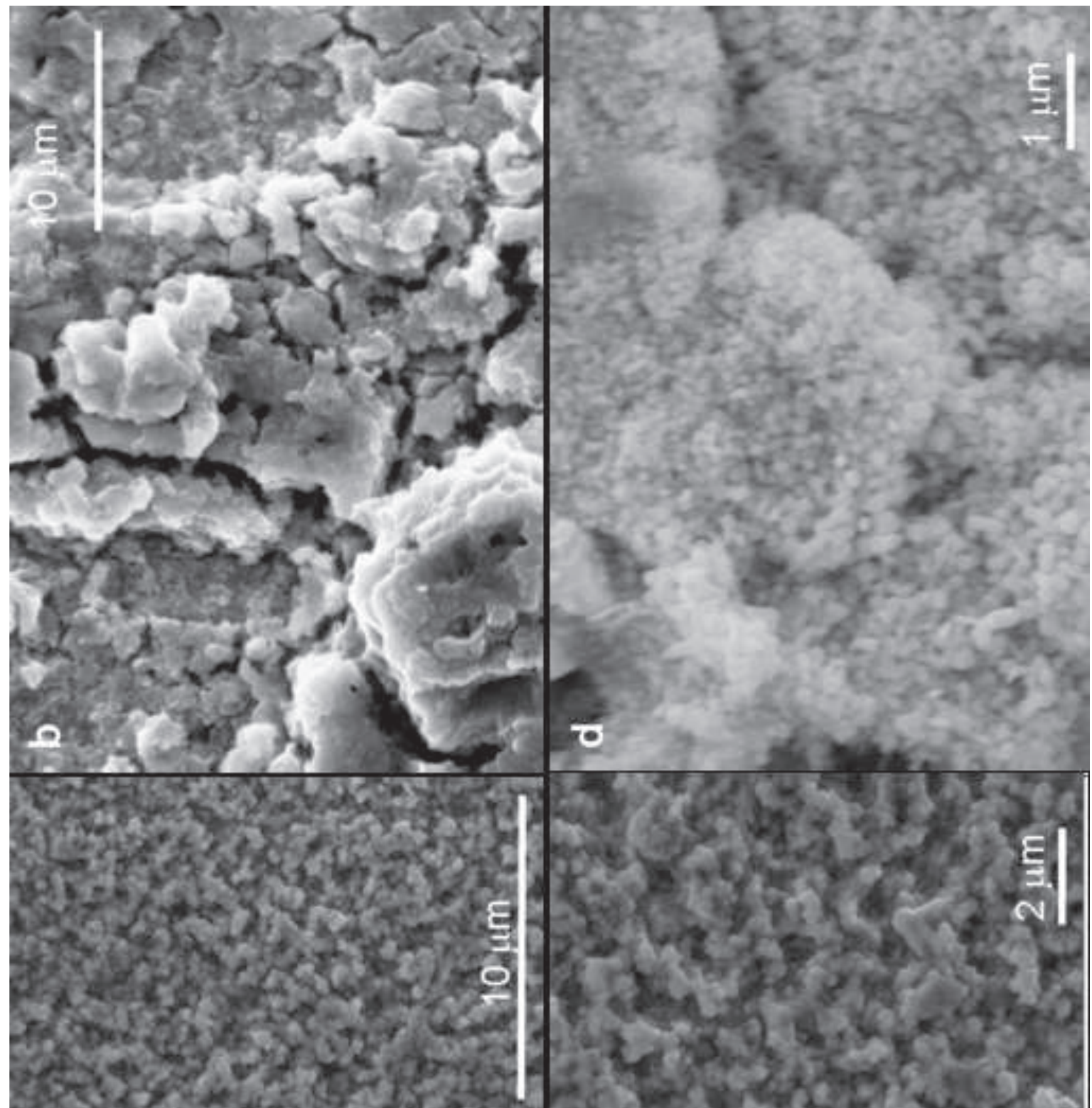

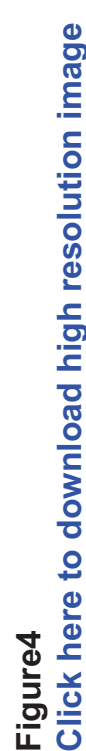

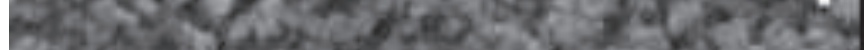

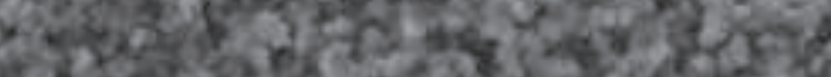

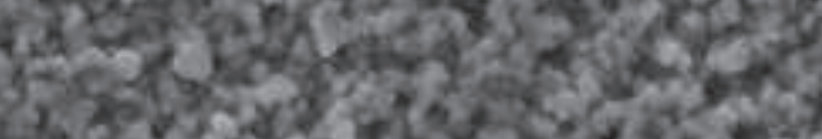

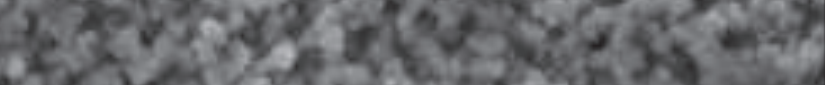

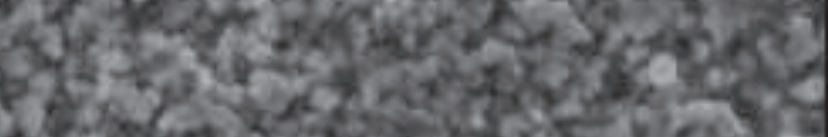

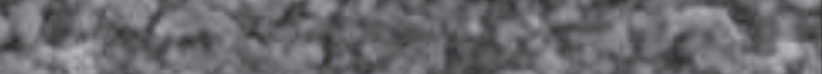

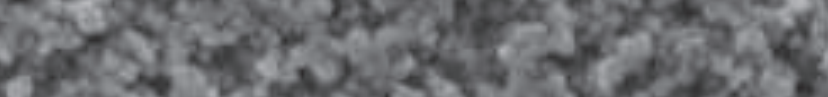

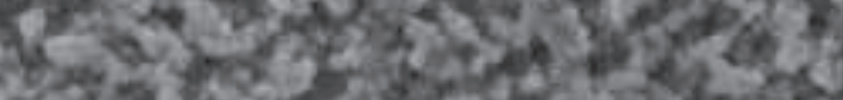
of 